\section{Another Year, Another Methodology: Are Rankings Telling Us Anything New?}

\section{Ellen Hazelkorn and Andrew Gibson}

Ellen Hazelkorn is policy advisor to the Higher Education Authority (Ireland), and Emeritus Professor and Director, Higher Education Policy Research Unit (HEPRU). E-mail: ellen.hazelkorn@dit.ie. Andrew Gibson is senior research assistant, HEPRU, and PhD candidate, Trinity College Dublin. E-mail: Andrew.gibson@dit.ie.

$\mathrm{P}$ reviously, when university rankings were discussed, one would have to start with the question "which one?" However, despite the fact that there are ten main global rankings, most attention is focused on: Academic Rankings of World Universities (ARWU), Times Higher Education, and QS. Yet, even after answering that first question, one can still ask, "yes, but which one?" This is because-between them-these three rankings have propagated 66 separate rankings and subrankings: rankings by region, by faculty, by field, by subject, and so on. All which goes to show that rankings are not just newsworthy, but also big business.

Traditionally, the focus of policy and media attention has been on the fascination and the melodrama of the relative volatility up or down-even by a statistically insignificant amount. Even students have been shown to make choices based upon such minor differences. Indeed, it is the sensationalism that accompanies such movement that has arguably helped drive the proliferation in the number and type of rankings, and especially the timing of their publication-which seems to coincide with major conferences or events.

Ranking organizations would dispute any deliberate intent. US News and World Report, for example, argued that modifications were a mark of improvement, or, as THE says, "change for the better." The latter has also justified such changes with reference to its various partnershipsits divorce from QS, its partnership with Thomson Reuters and most recently with Scopus.

\section{Recent Methodological Changes}

Methodological changes come in two broad forms. Changes can be structural: shifting weightings, specific indicators, "normalization" criteria, etc. by a few percentage points here or there. Or, there can be changes in the source data. Nonetheless, all this goes to highlight the arbitrariness of the methodology and the weightings.
In terms of source data, THE changed in 2015 from Web of Science (WoS) to Scopus. WoS includes only I2,000 journals compared with 23,000 in the latter. Scopus is regarded as giving better coverage to the humanities and social sciences, and so a broader range of universities' activities in more fields and subjects will be captured, chipping away at something of a science bias in the bibliometric indicators.

Another change effect was THE's decision to exclude papers with over I,००० authors on the basis that such publications could give a marginal institution outsize importance. This primarily affects fields such as particle physics, and, for example, projects from the European Organization for Nuclear Research (CERN). Without the full datasets being available, we have to assume that the exclusion of these research papers was responsible for the decline of Turkey's Boğaziçi University, which went from 139 in 20I4-20I5 to $501-600$ in 20I5-20I6. This raises questions about whether such research should now go completely unrecognized, and whether some alternative system might be a fairerand appropriate-solution.

\section{Traditionally, the focus of policy and me- dia attention has been on the fascina- tion and the melodrama of the relative volatility up or down-even by a statisti- cally insignificant amount.}

In 20I5, QS made changes to its methodology, which it called "refinements." The modification concerned how citations are calculated. Instead of having citations divided by the absolute number of researchers, it devised a model which normalized citation counts by field. This facilitated arts and humanities, social sciences, and engineering and technology research to rise to near parity with medicine and life/natural sciences. This means that universities with, for example, medical schools (which tend to be older and with a more established research reputation) will no longer be as advantaged, and newer institutions with strengths in other fields may rise. In an echo of THE's move, QS is also excluding papers with more than Io affiliated institutions.

In contrast, $A R W U$ 's methodology is fairly stable. Accordingly, major upsets are unusual, and the same universities feature in the top year after year. One change ARWU did make, in 2014 and 20I5, concerned how high citation papers (as captured by Thomson Reuters) are measuredwith specific reference to researchers with dual institutional affiliations. From 2003, ARWU used a list of 6,000 highlycited researchers, but a change in 2014 and 2015 introduced 
a shorter list with 3,000 researchers. This led to some minor changes in scores, but no great upsets.

The Russian Round University Ranking (RUR) uses data supplied by Thomson Reuters. Research and teaching are given equal weightings at 40 percent, with "international diversity" and "financial sustainability" comprising the remainder at Io percent each. An interesting point about this ranking, which is not otherwise groundbreaking, is that each university's scores for each indicator are available. This could make it an interesting alternative in an otherwise crowded market.

\section{Are These Changes Telling Us Anything New?}

There is plenty of international evidence showing how universities seek to manipulate or (more politely) influence their data. Because faculty numbers are a key denominator for research income, research students, publications, staff-student ratio, etc., there has been a consistent effort to recategorize faculty according to contract and employment status. There are determined efforts to clean up any mislabelling around institutional affiliation. There is also strong evidence around universities' efforts to raise student entry selectivity criteria, with knock-on implications for student completions, employability, and salary levels. While sensational, these examples are still relatively minor in the scheme of I 8,000 higher education institutions worldwide.

Despite these changes, it is not clear that the rankings are telling us anything we did not already know. Universities change so slowly that it is difficult to understand how the level of change portrayed in annual rankings can realistically be ascribed to the institutions themselves. Ironically, the problem of fluctuation threatens to obscure the converse problem: the relative uniformity of rankings. Despite the appearance of movement, rankings are remarkably consistent; different institutions may appear in slightly different order, but essentially the same institutions appear at or near the top in all rankings. This should not be surprising because rankings are essentially measuring the samewrong-things.

The tenacious "black box" nature of rankings depends upon governments, students, and the public not understanding or questioning what is inside.

\section{Citius, Altius, Fortius: Global University Rankings as the "Olympic Games" of Higher Education?}

\author{
Maria Yudkevich, Philip G. Altbach, and \\ LAURA E. RUMBLEY
}

Maria Yudkevich is vice rector of the National Research UniversityHigher School of Economics, Moscow, Russian Federation. E-mail: 2yudkevich@gmail.com. Philip G. Altbach is research professor and founding director of the Center for International Higher Education at Boston College. E-mail: altbach@bc.edu. Laura E. Rumbley is associate director of the Center for International Higher Education at Boston College.E-mail: laura.rumbley@bc.edu.

${ }^{1}$ Note: Citius, altius, fortius - Latin for "faster, higher, stronger"-is the official motto of the Olympic Games.

What's in a metaphor? There are many metaphors that can be, and frequently are, applied to global university rankings. From our perspective, there are many gamelike qualities to the global university rankings, and some notable parallels between these major academic contests and another key global competition: the Olympic Games.

Rankings, in parallel with the Olympics, are highly competitive, offering participants the potential to earn prestigious prizes or rewards, that can shape their prospects for the future in profound and quite tangible ways. For athletes, this may result in national and international fame and opportunities for lucrative endorsements. Similarly, universities demonstrating outstanding performance in the global rankings gain high international visibility; interest from desirable prospective students and faculty; money from private funding agencies, industry, philanthropists, as well as government.

\section{The Global Ran kings "Playing Field"}

Both the Olympics and the global university rankings pull together actors who share both an appreciation for the highest levels of performance on a worldwide stage, and a drive to compete to win. Not all entrants in these contests are created equal, however. To perform well in these elite international competitions, being smart and rich helps. Deep familiarity and experience with the rules of the game is also a key asset, as success often hinges on leveraging key strengths and minimizing troublesome weaknesses. 